\title{
Disability and Disaster: An Overview
}

David Alexander, University College London, U.K.

In most countries, people with disabilities make up between 10 and 20 per cent of the population, depending on how disability is classified and registered (WHO (2011) statistics give 7-10 per cent of the world's population as having disabilities, but it is likely that many remain uncounted, especially among the elderly). In emergencies, people with disabilities may encounter physical barriers, obstacles to communication and other barriers to accessing essential services (Figure 1). Hence, they may easily suffer greater discrimination, as well as lower levels of protection against disaster, than those offered to people without disabilities.

The predicament of people with disabilities in disaster has been graphically described by Hemingway and Priestley (2006, p. 64):

Disabled people have been made more vulnerable to natural hazards through historical processes of exclusion and impoverishment. As a consequence, their experience of disaster may be more acute and long-standing than [that of] nondisabled populations. These effects are accentuated in poor communities throughout the world where disabled people remain amongst the poorest of the poor. Moreover, when disaster strikes, disabled people encounter inequities in access to shelter or relief and are often excluded from full participation in response and recovery.

This chapter considers the wide range of types of disability in the context of disaster. 


\section{What is disability?}

The fact that up to a fifth of the population may be regarded as having disabilities reflects the very wide range of states and conditions that affect individuals in disaster risk reduction and disasters. These are catalogued and described in the WHO International Classification of Functioning, Disability and Health (WHO 2010). Moreover, disability may be temporary, as with a broken leg, or permanent, as in the case of an irreparable spinal injury. Perhaps the most visible form of disability involves reduced mobility, but there are many other types, for example: paraplegia, quadriplegia, deafness, blindness, mental retardation, brain damage, stroke, age-related infirmity, senility, Alzheimer's disease, or dependence on life-support machines.

The following list illustrates the variety of forms of disability:

- restricted mobility

- blindness or partial sight

- deafness and hearing impairment

- difficulties of cognition, communication, and expression

- medical problems

- use of support systems to maintain vital functions

- intolerance of environmental and chemical substances

- psychiatric disturbances and panic attacks

- health issues associated with old age

These categories are not necessarily comprehensive or mutually exclusive. 
Disability may result from a hereditary condition, injury, illness, or advancing age. The degree of autonomy that people with disabilities enjoy, or the support that they require, is also highly variable from one instance to another.

It is evident that the ability of someone to perceive a threatening situation, and react to it, varies with the form of disability. For example, people who use wheelchairs may have significant problems sheltering under desks and tables during earthquakes (Rahimi 1993). In seismic events, fires or structural collapses, they may be forced to take to elevators to leave buildings even though the use of such equipment is severely discouraged in the general population — or else be reliant on others to carry them out. People with deficient sight or hearing may be unable to recognize the signs of danger or any orders to evacuate, if the messages are not provided in forms suitable for those people. For people who cannot walk unaided, difficulties of movement can involve problems with the narrowness of passages and doorways, the presence of steps or other obstacles and the unsuitability of lifts and ramps (Tierney et al. 1988). People with disabilities who depend on electrically-powered life-support equipment may find themselves in difficulty if there is no or intermittent power. Moreover, emergency equipment should be made accessible to people with disabilities, including, where appropriate, alarms and means of calling for assistance. In synthesis, evacuation problems can involve difficulties of orientation or movement, problems of perception regarding hazards and warnings and special needs concerning the co-ordination of emergency response (Christensen et al. 2007).

Disability resulting from disaster 
Disability can also be caused by disaster. In earthquakes, crush injuries can necessitate amputations and a bad fall can lead to permanent damage to the spine. Moreover, crush syndrome can cause kidney or heart failure (Sever 2006). However, the number of cases is small relative to the overall total numbers of injuries. The risk of permanent disability is much higher with bomb attacks as these can cause a wide variety of injuries. They include blast effects within the body (barotrauma), penetrating injury from shrapnel, fragmentation of bones, severe burns and damage to the lungs. Soft tissue cannot easily withstand the effects of a blast that may reach 26 atmospheres (2.6 MPa). Nevertheless, the medical effects of bombs tend to decrease exponentially with distance from the location of the blast, unless it is reflected off hard surfaces. Bombs that do the most damage to people tend to be those that are detonated in crowded internal spaces.

A more constant source of disability is the presence of unexploded ordinance (UXO) such as landmines (anti-personnel mines) and cluster bombs. About a quarter of the cluster munitions dropped on Laos by the USA over the period 1968-70 failed to explode. Laos was left with a legacy of 288 million cluster munitions and 75 million unexploded bombs, which for years caused an average of 10,000 deaths and a similar number of injuries per annum. Demand for prosthetic limbs remained insatiably high, as it does in Sierra Leone, where conflict was associated with deliberate maiming of civilians. These situations are 'disasters' as much as are earthquakes, floods and conventional conflict. Moreover, floods and accelerated erosion can translocate UXO and make it difficult to detect and neutralize before a civilian encounters it and is injured. 
It is clear from many examples of the difficulties experienced by people with disabilities that they may encounter new and unforeseen obstacles when disasters occur. There is no moral or ethical justification for suspending anti-discrimination measures because a state of emergency prevails. Hence, it is vital to ensure that people with disabilities are given full consideration in emergency preparedness. Sadly, there are very many cases in which this is not the case. Some elements of the problem may be the result of lack of funds or poor fund allocation, but unfortunately most are the result of ignorance or indifference by policy makers, planners and emergency responders. The onus to prepare for disasters may also fall upon people with disabilities and those who care for them, who may share that responsibility with emergency responders.

\section{Disability and disaster reduction}

The main difference between disaster management and response for the general public and measures designed to assist people with disabilities is that the former can be catered for with general and generic provisions while many of the latter require specific modifications to the measures to ensure full inclusivity. This involves a fundamental reorientation in the nature of emergency planning, from assisting groups of people (the general public) to providing help to single individuals that is tailored to their specific needs. This is the only way towards achieving the full integration of people with disabilities into society and affirming their rights as full citizens.

In disasters it is easy to mistake the type of disability of a person and thus offer the wrong kind of assistance. This especially true of those disabilities that are not obvious to responders, 
such as the ones associated with certain forms of mental health. Hence, disasters and their aftermaths can put people with disabilities more at risk than are the general population and may create new barriers. The key to the success of measures is to prepare before disaster strikes, as assistance to people with disabilities is especially difficult to improvise during an emergency.

One of the most common situations in which people with disabilities are likely to be involved in is mass evacuation; for example, before storms or floods. As a general principle, evacuation should only be attempted if there is time to complete it before disaster strikes (Assavapokee et al. 2010). This requires adequate warning and lead times, as well as appropriate awareness and organization. People with disabilities may require more time and resources than the ablebodied if they are to complete evacuation on the same level (Christensen et al. 2007).

In disasters, people with disabilities may need to ensure that they can take personal care materials and equipment with them if they have to evacuate their homes. If they do not need to evacuate, they may need advice and assistance on how to cope with chaotic situations at home. Help with transport and mobility is one of the most common requirements, and at an elementary level how to communicate need and ask for assistance, or who to contact in an emergency are basic matters that need to be resolved. Moreover, people with disabilities may have a high degree of dependence on essential services, such as water and electricity supplies especially for medical support including ventilators and dialysis. If these fail, alternative arrangements may need to be made as a matter of priority. Finally, one also has to remember the needs of guide dogs for the blind (FEMA/ARC 2005) and other service dogs, such as dogs for people with wheelchairs, seizure dogs, and hearing dogs. 
The description of needs should not be interpreted as a call to increase the level of dependency of people with disabilities. Many of those who have some level of autonomy are resourceful and accustomed to adversity, such that they have a potential psychological advantage over people without disabilities when disaster strikes (Lathrop 1994). Moreover, many people with disabilities live in the community, either autonomously or cared for by close relatives, rather than living in an institutional setting. This helps moderate the degree of dependency, but perhaps it increases the number of people who need to consider what should be done to care for people with disabilities with respect to disaster risk.

The process of creating emergency plans that include people with disabilities requires a fundamental reorientation of approach. Typically, civil protection systems are designed for people without disabilities. For example, evacuation plans require, in some measure, the ability to walk, drive, see and hear. In contrast, the evacuation of a nursing home for the elderly is a challenging process that requires considerable resources and time, which makes it imperative, not only to avoid overlooking such places, but also to give them priority in early warning (McGuire et al. 2007). In emergency planning, no single strategy is valid for all types of disability. Hence, measures need to be as varied as they are sensitive to the range of needs to be addressed. Moreover, it is important to distinguish the needs of people with disabilities from those of other disadvantaged groups, such as ethnic minorities, single mothers, and people with special dietary or medical needs.

The extent to which people with disabilities can prepare for disaster is governed by the nature of their disabilities and the level of support received from outside agencies. Where personal 
preparedness is possible (i.e. the person with a disability enjoys a certain degree of autonomy), the act of preparing would usually be a collaborative one that involves professional carers and perhaps disaster managers or potential first responders. Indeed, the ideal situation is one in which volunteer organizations, civil protection volunteer organizations, local authority social services, local emergency planners and local health districts are all involved in the preparations. More commonly, as is typical of the NGO world, there is an unfortunate lack of integration and cooperation among organizations that assist people with disabilities and those that provide civil protection services.

One of the principal problems associated with emergency planning for people with disabilities is lack of interest, involvement and understanding. A survey conducted by the US Federal Emergency Management Agency (NCD 2005) showed that four out of five emergency planners contacted had devised no special procedures for people with disabilities. Some 57 per cent did not know how many people with disabilities lived in the areas they worked in, and barely one in four had taken a FEMA course on helping people with disabilities in disasters. This reveals a low level of preparedness and sensitivity to the problem, yet in a country in which 19.3 per cent of the population is registered as having a disability (WHO 2011, p. 276).

Hence for emergency planners the first hurdle is to raise awareness such that efforts are made to think about the question of disaster preparedness for people with disabilities. The second step is to obtain information on where people with disabilities are located, and what are their disabilities. Nursing homes for the elderly are particularly significant here (Fernandez et al 2002). If they need to be evacuated, considerable human effort and resources are required. In 
many countries in disasters, volunteer organizations are the key to successfully supporting people with disabilities.

The second problem is lack of appreciation of what is required in the planning process. A fundamental necessity is to base measures on evidence and hard information. The influential U.S. report entitled Nobody Left Behind: Investigating Disaster Preparedness and Response for People with Disabilities argued that "in practice, empirical data on the efficient and secure evacuation of disabled people during emergencies and crises do not exist" (White et al. 2004). There is thus a need to conduct research on the problem and to feed the results back into planning in order to ensure that it is realistic.

A basic principle of emergency planning for people with disabilities is to ensure that procedures and services which are there at normal times are still accessible during emergencies. Furthermore, emergency communications with people with disabilities need to be accessible and reliable. This is especially true for those who have impaired sight, hearing or speech. Planning, preparing, training and exercising should be conducted together with carers and associations for people with disabilities, in a way that, wherever possible, people with disabilities know what to do in particular emergency situations (Rowland et al. 2007). It also helps to involve the mass media in the transmission of warnings to people with disabilities wherever special services are available, such as television services for the hard-ofhearing (NCD 2009).

People with disabilities should attempt to gain an understanding of how they might have to react to a developing emergency when they are at work or at home. FEMA/ARC (2005) 
recommended that they create personal support networks composed of at least three ablebodied people per site. They should estimate their own capacity to respond to an emergency and if the risks of disaster are significant they should wear a label or bracelet to identify the form of their disability. FEMA/ARC recommends that each person with disabilities who is able to should create a personal emergency plan and involve members of his or her support network in it.

Emergency responders should be trained in how to deal with people with disabilities in crisis situations. This can include techniques for lifting people in such a way as to avoid harm to both the lifter and the person being lifted. Responders should be made aware of the need to preserve the dignity of people with disabilities and to treat them fairly. Training should be divided between awareness raising and technical issues. The former should include information on the range of needs and points of view of people with disabilities.

Disaster aftermaths may be periods in which people with disabilities suffer particular forms of discrimination. For example, temporary housing has been provided that is not wheelchair accessible. As Hemingway and Priestley (2006) noted, people with disabilities may be poor and generally disadvantaged as a result of their disabilities. The restrictions posed by difficult situations that arise after disaster can worsen this effect if support and assistance, both medical and social, are not forthcoming.

\section{Legal instruments and documents}


Much of the preceding discussion has to do with rights. These are safeguarded by legal requirements and other official instruments.

One of the most powerful and comprehensive legislative instruments to deal with the rights of people with disabilities is the US “Americans with Disabilities Act" of 1990, amended in 2008 (US Government 1990, Jones 2010). This is an anti-discriminatory measure comparable to the US Civil Rights Act, and it applies to the 54.4 million US citizens who are registered as having a disability. Although it has no specific provisions on the plight of people with disabilities in disasters, the requirements to reduce or abolish discrimination are clearly significant in relation to disaster management. In July 2005, President Bush issued an executive order to operationalize the Act under emergency conditions (US DHS 2005). This document required federal government departments to plan for people with disabilities and to give them priority in communications, transportation and shelter after disaster.

When Hurricane Katrina struck the Gulf states of the USA in August 2005, 155,000 residents of Biloxi (MS), Mobile (AL), and New Orleans (LA) were registered as having disabilities (White 2007). In the aftermath of the disaster it was estimated that a quarter of the displaced survivors were people with disabilities (a significant number of others had died as a result of neglect and failure to rescue them, which became a national scandal).

Shortly after Katrina, the US Department of Justice issued practical guidelines on how to assist people with disabilities during national emergencies (US DoJ 2006). As in most such documents, the emphasis was on physical disability, particularly blindness or need to use a wheelchair. In 2009, a larger report was issued by the US National Council on Disability, 
which comprehensively evaluated the status and prospects of the US people with disabilities and their communities during and after major incidents and disasters (US NCD 2009).

Despite these developments, a report published four years after Katrina (LaCheen 2010) accused FEMA of ignoring the needs of people with disabilities. There appeared to be a large gap between rhetoric and reality. FEMA had established a network of functionaries with responsibility for responding to the needs of people with disabilities in disaster, but not much appeared to have come of it. The National Center for Law and Economic Justice argued that through its inaction FEMA remains in breach of the Americans with Disabilities Act. Nonetheless, the negative example of Hurricane Katrina did galvanize many of the US agencies that work in disaster to take seriously the issue of how to assist people with disabilities. In fact, in response to the inadequacy of arrangements after Katrina, FEMA issued a reference guide for public administrators and emergency responders (FEMA 2007) to acquaint them with the ethical and legal requirements for accommodating people with disabilities in post-disaster situations.

In many other places, the official picture is bleak. The Indian Government's manual of standard operating procedures to respond to natural disasters (Government of India 2010) makes no mention of the plight of the country's 90 million people with disabilities (Alur 2002). Indeed, it is only since 2012 that the appalling security risks to women have begun to be taken seriously in India, once dubbed "the worst country in which to be a woman" (Asch et al. 2001). 
Where government neglects the problem, it is left to non-governmental organizations to act. Working in Nepal, Handicap International has produced a manual that is designed to help make disability a mainstream issue in disaster risk reduction. The manual is a training instrument that is rich in information (Handicap International 2009). A similar document has been produced for the Caribbean, but is restricted to the disabilities suffered by elderly people (PAHO 2012). Moreover, the Sphere Humanitarian Charter and Minimum Standards in Humanitarian Response make abundant reference to disabilities, and the need both to protect people with disabilities and to take full account of them in disaster risk reduction and disaster response initiatives (Sphere Project 2011).

The Sphere standards (Sphere Project 2011) treat disability as a cross-cutting issue that interacts with many other aspects of humanitarian practice. The standards recommend that proper attention be given to people with disabilities, that facilities be designed with their needs in mind, and made accessible to them, that their vulnerability receive a proper assessment, that they are fully included in communication initiatives, that their well-being and nutrition be monitored, and in short that efforts be made to ensure that they receive their entitlements in full. The standards (Sphere Project 2011, p. 223) note that people with disabilities are often excluded from anthropometric surveys of nutritional status, largely because no information exists on how to include them.

Article 11 of the UN Convention on the Rights of Persons with Disabilities and Optional Protocol states as follows:

States Parties shall take, in accordance with their obligations under international law, including international humanitarian law and international 
human rights law, all necessary measures to ensure the protection and safety of persons with disabilities in situations of risk, including situations of armed conflict, humanitarian emergencies and the occurrence of natural disasters. (UN Enable, 2007, p. 10).

In the Asia-Pacific region, this is backed up by the Biwako Millennium Framework for Action on the reduction of barriers to people with disabilities (UNESCAP 2012). It remains to be seen to what extent the provisions of these instruments will be operationalized with respect to major emergencies and disaster risk.

Meanwhile, European countries produced the "Verona Charter", which lays down requirements for the rescue and evacuation of people with disabilities in disaster (ULSS20 Verona 2007). This document, which is fairly general in scope, is mainly intended for the emergency and health services and does not consider the more comprehensive field of disaster risk reduction, but only the emergency phase and associated planning requirements. One other European document of interest is the Irish Government's set of guidelines on how to design buildings to ensure that people with disabilities can get out of them safely during an emergency (NDA 2008).

This brief and incomplete review of official national and international documents suggests that there are plenty of good models to guide the process of caring for people with disabilities in the context of disasters and disaster risk reduction. These include legal frameworks, practical manuals and strategic surveys. However, there is clearly an 'adoption gap' that separates the ideal situation from what one encounters on the ground. Official indifference 
still proliferates, as does ignorance of the disaster-related needs of people with disabilities. Nevertheless, awareness is slowly growing at the organizational level, helped by positive and negative examples, and by efforts to disseminate information. All countries should have a legal requirement to assist people with disabilities, and in every case it should be clear that this extends to disasters, emergencies and their recovery periods. In many cases, the next step should be to ensure concerted action by consortia of governmental and non-governmental organizations, leading to the gradual 'normalization' of care for people with disabilities during disasters.

\section{Conclusions}

In most countries, one-in-six to one-in-five people live with at least one disability. Disabilities take many forms and their requirements for technical and social assistance can be complex. Moreover, those populations in which the number and proportion of elderly people is rising are likely to increase the number of people with disabilities in the population.

It is a fundamental ethical principle that people with disabilities have an equal right to disaster assistance programs. If the medical, social, economic and technical means to make their lives relatively normal exist, then they should be employed to the full. Arguments about prohibitive costs and the burden on the rest of society have been shown to have little value, as even expensive measures pay back immensely over time by having people with disabilities fully integrated into society. The care of people with disabilities and their acceptance as full members of society requires a certain mindset that is gradually gaining in dominance. There is no justification for relaxing basic principles when disaster strikes. 
Sadly, research on people with disabilities and disasters is in short supply. This means that situations, accusations and assumptions are unverified. Nevertheless, from an unclear picture, it seems that the greatest need at present is to improve coordination among the agencies that deal with the needs of people with disabilities. These include volunteer organizations for both civil protection and people with disabilities, and social services in health and local authority (Figure 2).

There is a moral imperative to guarantee assistance in disasters to people with disabilities and to reduce, with a view to eliminating, the constructed barriers and sources of discrimination that put them at a disadvantage in emergencies and disasters. People with disabilities are very much a part of society and many of them play full roles in it. The rise of the Paralympic Games has helped gain public acceptance of people with disabilities, but there is still much to do to ensure that their concerns are taken fully into consideration for disasters and disaster risk reduction.

\section{References}

Alur, N. 2002. 'They did not figure': policy exclusion of disabled people in India. International Journal of Inclusive Education 6(2): 101-112.

Asch, A., T.S. Perkins, M. Fine and H. Rousso 2001. Disabilities and women: deconstructing myths and reconstructing realities. In J. Worrell (ed.) Encyclopedia of Women and Gender, Vol. 1. Academic Press, New York: 345-354. 
Assavapokee, T., G.J. Lim, A.K. Kamrani and H.R. Parsaei 2010. Emergency Evacuation Planning and Management (Engineering and Management Innovation). CRC Press, Boca Raton, 350 pp.

Christensen, K.M., M.E. Blair and J.M. Holt 2007. The built environment, evacuations, and individuals with disabilities: a guiding framework for disaster policy and preparation. Journal of Disability Policy Studies 17(4): 249-254.

FEMA 2007. Accommodating Individuals With Disabilities In The Provision Of Disaster Mass Care, Housing, And Human Services. US Federal Emergency Management Agency, Washington, DC, $32 \mathrm{pp}$.

FEMA/ARC 2005. Preparing for Disaster for People with Disabilities and Other Special Needs. American Red Cross and US Federal Emergency Management Agency, Washington, DC, 18 pp.

Fernandez, L.S., D. Byard, C-C. Lin and S. Benson 2002. Frail elderly as disaster victims: emergency management strategies. Prehospital and Disaster Medicine 17(1): 67-74.

Government of India 2010. Standard Operating Procedure for Responding to Natural Disasters. Disaster Management Division, Ministry of Home Affairs, Government of India, New Delhi, 84 pp. 
Handicap International 2009. Mainstreaming Disability into Disaster Risk Reduction: A Training Manual. Handicap International, Kathmandu, Nepal, 78 pp.

Hemingway, L. and M. Priestley 2006. Natural hazards, human vulnerability and disabling societies: a disaster for disabled people? Review of Disability Studies 2: 57-67.

Jones, N.L. 2010. The Americans with Disabilities Act and Emergency Preparedness and Response. Congressional Research Service, Washington, DC, 8 pp.

LaCheen, C. 2010. More than five years after Katrina, FEMA is not prepared to meet the temporary housing needs of people with disabilities and others after a disaster. National Center for Law and Economic Justice, New York, 8 pp.

Lathrop, D. 1994. Disaster! If you have a disability, the forces of nature can be meaner to you than anyone else. But you can fight back. Be prepared. Mainstream, November 1994. www.accessiblesociety.org/topics/independentliving/disaster.htm Accessed 14 May 2013.

McGuire, L.C., E.S. Ford and C.A. Okoro 2007. Natural disasters and older US adults with disabilities: implications for evacuation. Disasters 31(1): 49-56.

NCD 2005. Saving Lives: Including People with Disabilities in Emergency Planning. US National Council on Disability, Washington, DC. 
NCD 2009. Effective Emergency Management: Making Improvements for Communities and People with Disabilities. US National Council on Disability, Washington, DC, 510 pp.

NDA 2008. Promoting Safe Egress and Evacuation for People with Disabilities. National Disability Authority of Ireland, Dublin, 139 pp.

PAHO 2012. Guidelines for Mainstreaming the Needs of Older Persons in Disaster Situations in the Caribbean. Area on Emergency Preparedness and Disaster, Pan American Health Organisation, Washington, DC, $78 \mathrm{pp}$.

Rahimi, M. 1993. An examination of behaviour and hazards faced by physically disabled people during the Loma Prieta earthquake. Natural Hazards 7(1): 59-82.

Rowland, J.L., G.W. White, M.H. Fox and C. Rooney 2007. Emergency response training practices for people with disabilities: analysis of some current practices and recommendations for future training programs. Journal of Disability Policy Studies 17(4): 216-222.

Sever, M.S., R. Vanholder and N. Lameire 2006. Management of crush-related injuries after disasters. New England Journal of Medicine 354(10): 1052-1063.

Sphere Project 2011. Humanitarian Charter and Minimum Standards in Humanitarian Response. The Sphere Project, Geneva, Practical Action Publishing, Rugby, UK, 393 pp. 
Tierney, K., W. Petak and H. Hahn 1988. Disabled Persons and Earthquake Hazards. Monograph no. 46, Institute of Behavioral Science, Program on Environment and Behavior, University of Colorado, Boulder, Colorado, $150 \mathrm{pp}$.

ULSS20 Verona 2007. "Verona Charter" on the Rescue of Persons with Disabilities in Case of Disasters. Declaration of the participants in the Consensus Conference held in Verona on 8-9 November 2007. Unità Locale di Servizi Sanitari n. 20, Verona, Italy, 17 pp.

UN Enable 2007. Convention on the Rights of Persons with Disabilities and Optional Protocol. UN Enable, United Nations Organisation, Geneva, 37 pp.

UNESCAP 2012. Biwako Millennium Framework for Action. United Nations Economic and Social Commission for Asia and the Pacific, Incheon, South Korea, 19 pp.

US DHS 2005. Individuals with Disabilities in Emergency Preparedness. Executive Order 13347. US Department of Homeland Security, Washington, DC, 48 pp.

US DoJ 2006. Making Community Emergency Preparedness and Response Programs Accessible to People with Disabilities. Civil Rights Division, US Department of Justice, Washington, DC, $11 \mathrm{pp}$.

US Government 1990 (Amended 2008). An Act to establish a clear and comprehensive prohibition of discrimination on the basis of disability [the Americans with Disabilities Act], Public Law 101-336. Congress, Washington, DC, 58 pp. 
US NCD 2009. Effective Emergency Management: Making Improvements for Communities and People with Disabilities. US National Council on Disability, Washington, DC, 510 pp.

White, G.W. 2007. Katrina and other disasters: lessons learned and lessons to teach. Journal of Disability Policy Studies 17: 194-195.

White, G., M. Fox, J. Rowland, C. Rooney and S. Aldana 2004. Nobody Left Behind: Investigating Disaster Preparedness and Response for People with Disabilities. Research and Training Center on Independent Living, University of Kansas, Lawrence, Kansas, 31 pp.

WHO 2010. International Classification of Functioning, Disability and Health. World Health Organization, Geneva, 303 pp.

WHO 2011. World Report on Disability. World Health Organization, Geneva, and World Bank, New York, 325 pp.

\section{List of figures}

Figure 1. A person with a physical disability confronts a physical barrier at an evacuation center during an emergency simulation exercise. Fortunately, the problem was resolved with ingenuity and good humor. (Photo: Author) 
Figure 2. Integrating the forces when planning to assist people with disabilities for disaster risk reduction and disasters.
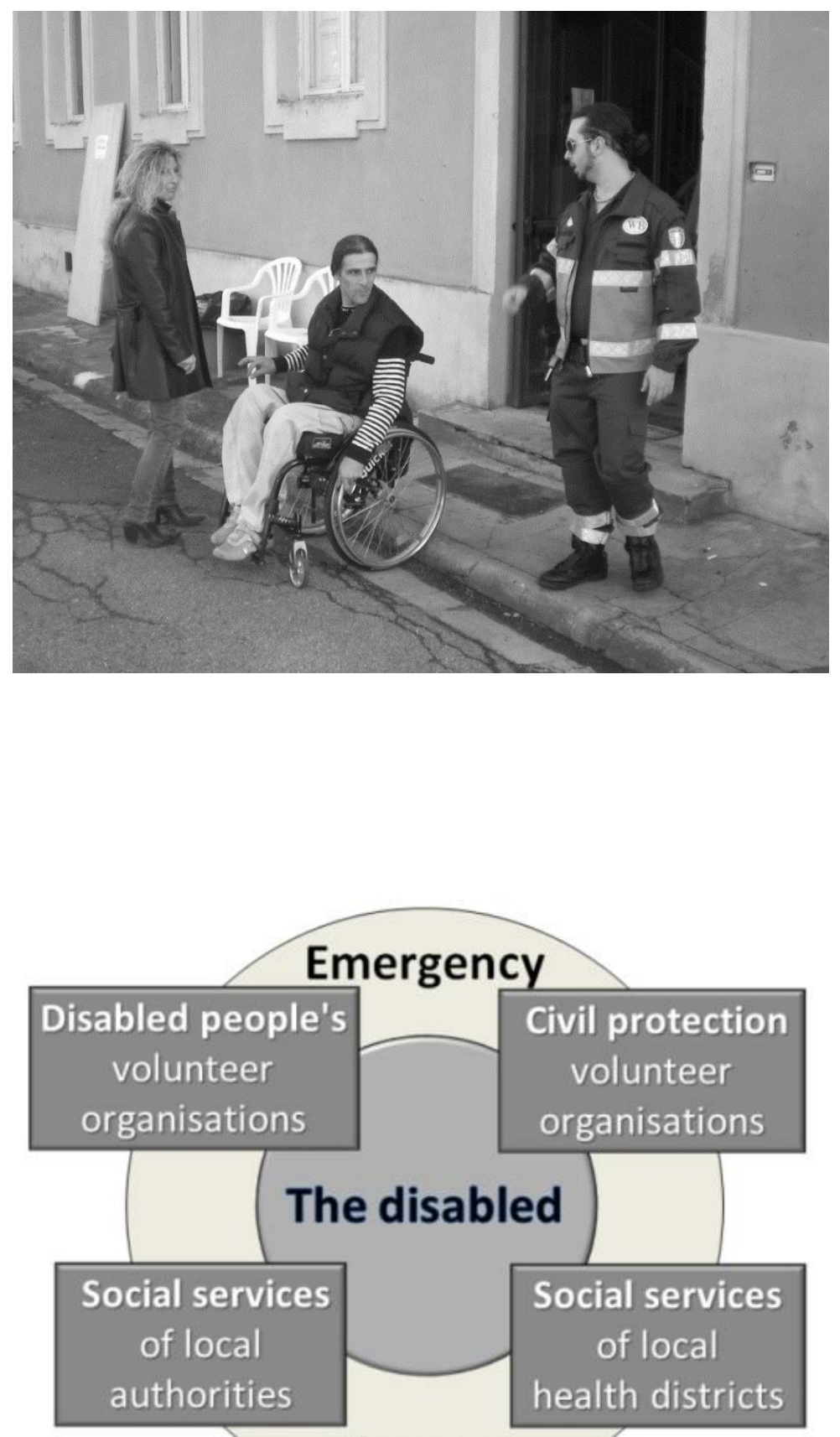

\section{Planning}

